\title{
Contemporary horizontal crustal movement estimation for northwestern Vietnam inferred from repeated GPS measurements
}

\author{
Nguyen Anh Duong ${ }^{1,2}$, Takeshi Sagiya ${ }^{2}$, Fumiaki Kimata ${ }^{3}$, Tran Dinh To ${ }^{4}$, Vy Quoc Hai ${ }^{4}$, \\ Duong Chi Cong ${ }^{5}$, Nguyen Xuan Binh ${ }^{1}$, and Nguyen Dinh Xuyen ${ }^{1}$ \\ ${ }^{1}$ Institute of Geophysics, Vietnam Academy of Science and Technology, Bldg. A8, 18 Hoang Quoc Viet Street, Cau Giay, Hanoi, Vietnam \\ ${ }^{2}$ Nagoya University, D2-2 (510), Furo-cho, Chikusa-ku, Nagoya, Aichi 464-8601, Japan \\ ${ }^{3}$ Tono Research Institute of Earthquake Science, 1-63 Yamanouchi, Akeyo-cho, Mizunami 509-6132, Japan \\ ${ }^{4}$ Institute of Geological Sciences, Vietnam Academy of Science and Technology, 84 Chua Lang Street, Dong Da, Hanoi, Vietnam \\ ${ }^{5}$ Vietnam Institute of Geodesy and Cartography, 479 Hoang Quoc Viet Street, Cau Giay, Hanoi, Vietnam
}

(Received June 16, 2013; Revised September 2, 2013; Accepted September 16, 2013; Online published December 6, 2013)

\begin{abstract}
We present a horizontal velocity field determined from a GPS network with 22 sites surveyed from 2001 to 2012 in northwestern Vietnam. The velocity is accurately estimated at each site by fitting a linear trend to each coordinate time series, after accounting for coseismic displacements caused by the 2004 Sumatra and the 2011 Tohoku earthquakes using static fault models. Considering the coseismic effects of the earthquakes, the motion of northwestern Vietnam is $34.3 \pm 0.7 \mathrm{~mm} / \mathrm{yr}$ at an azimuth of $\mathrm{N} 108^{\circ} \pm 0.7^{\circ} \mathrm{E}$ in ITRF2008. This motion is close to, but slightly different from, that of the South China block. The area is in a transition zone between this block, the Sundaland block, and the Baoshan sub-block. At the local scale, a detailed estimation of the crustal deformation across major fault zones is geodetically revealed for the first time. We identify a locking depth of $15.3 \pm 9.8 \mathrm{~km}$ with an accumulating left-lateral slip rate of $1.8 \pm 0.3 \mathrm{~mm} / \mathrm{yr}$ for the Dien Bien Phu fault, and a shallow locking depth with a right-lateral slip rate of $1.0 \pm 0.6 \mathrm{~mm} / \mathrm{yr}$ for the Son La and Da River faults.
\end{abstract}

Key words: Crustal movement, GPS, coseismic offset, earthquake, northwestern Vietnam.

\section{Introduction}

The northwestern Vietnam (NWV) study area is located in the southeastern part of the Eurasian plate (DeMets et al., 1994). The NWV appears to form a border between the South China block (SC) (Shen et al., 2005) and the Sundaland block (SU) (Simons et al., 2007) (Fig. 1). The northward motion of the Indian-Australian plate with respect to the Eurasian plate (EU) has caused the east-southeastward extrusion of Southeastern Asia (Molnar and Tapponnier, 1975; England and Molnar, 1997). In these models, the Red River Fault (RRF) in northern Vietnam is regarded as the northeastern tectonic boundary between SC and SU accommodating right-lateral shear strain (Wilson et al., 1998; Michel et al., 2001; Kreemer et al., 2003; Simons et al., 2007). Meanwhile, Bird (2003) and McCaffrey (2009) suggested that this boundary is located farther south. Because of the slow relative motion between the SU and SC blocks and the scarcity of precise space geodetic measurements in this area, the actual location of the tectonic boundary is still uncertain. Thus, a dense GPS observation network in NWV can provide an insight into the tectonic deformation of this region, as well as Southeast Asia.

NWV is a mountainous region with a complicated geological structure, dominated by many active faults, such as the Dien Bien Phu Fault (DBPF), the Son La Fault (SLF),

Copyright (c) The Society of Geomagnetism and Earth, Planetary and Space Sciences (SGEPSS); The Seismological Society of Japan; The Volcanological Society of Japan; The Geodetic Society of Japan; The Japanese Society for Planetary Sciences; TERRAPUB.

doi:10.5047/eps.2013.09.010 the Ma River Fault (MRF), the Da River Fault (DRF), and the Red River Fault (RRF). This region is the most seismically active in Vietnam. According to Son (2012), at least 331 earthquakes with a local magnitude of 3.0-6.8 occurred from 1903 to April 2012 in the vicinity of these fault zones (Fig. 2). There were two large earthquakes, the 1935 Dien Bien earthquake ( $M$ 6.75, GUTE) and the 1983 Tuan Giao earthquake $\left(M_{\mathrm{w}} 6.2, \mathrm{HRV}\right)$, which caused great damage to houses and infrastructure, as well as killing or injuring dozens of people in landslides (Thuy, 2005).

GPS measurements in NWV started in 2001. Initial results from small local networks located in the DBPF zone (Duong et al., 2006) and SLF-DRF-RRF zones (Tran, 2006) could not reveal a clear deformation pattern related with the fault systems. Recently, Lai et al. (2012) combined the velocity solutions of Duong et al. (2006) and Shen et al. (2005) to evaluate the deformation of DBPF and reported a slip rate of $2-3 \mathrm{~mm} / \mathrm{yr}$. This result may be overestimated in Vietnam since the GPS sites used by Shen et al. (2005) are close to the northern segment of RRF or the XianshuiheXiaojiang fault in south China, where tectonic deformation is more active than in NWV. Thus, a GPS network of a higher level of accuracy, spatial resolution, and longer time span is required to resolve the small motions in this area. Since 2009, besides maintaining the 2001 GPS sites, we have deployed an expanded GPS network with new campaign sites in NWV around the SLF-DRF zone, resulting in a unique GPS data set spanning from 2001 to 2012, including 22 campaign sites in total.

During the GPS campaigns, three great earthquakes oc- 


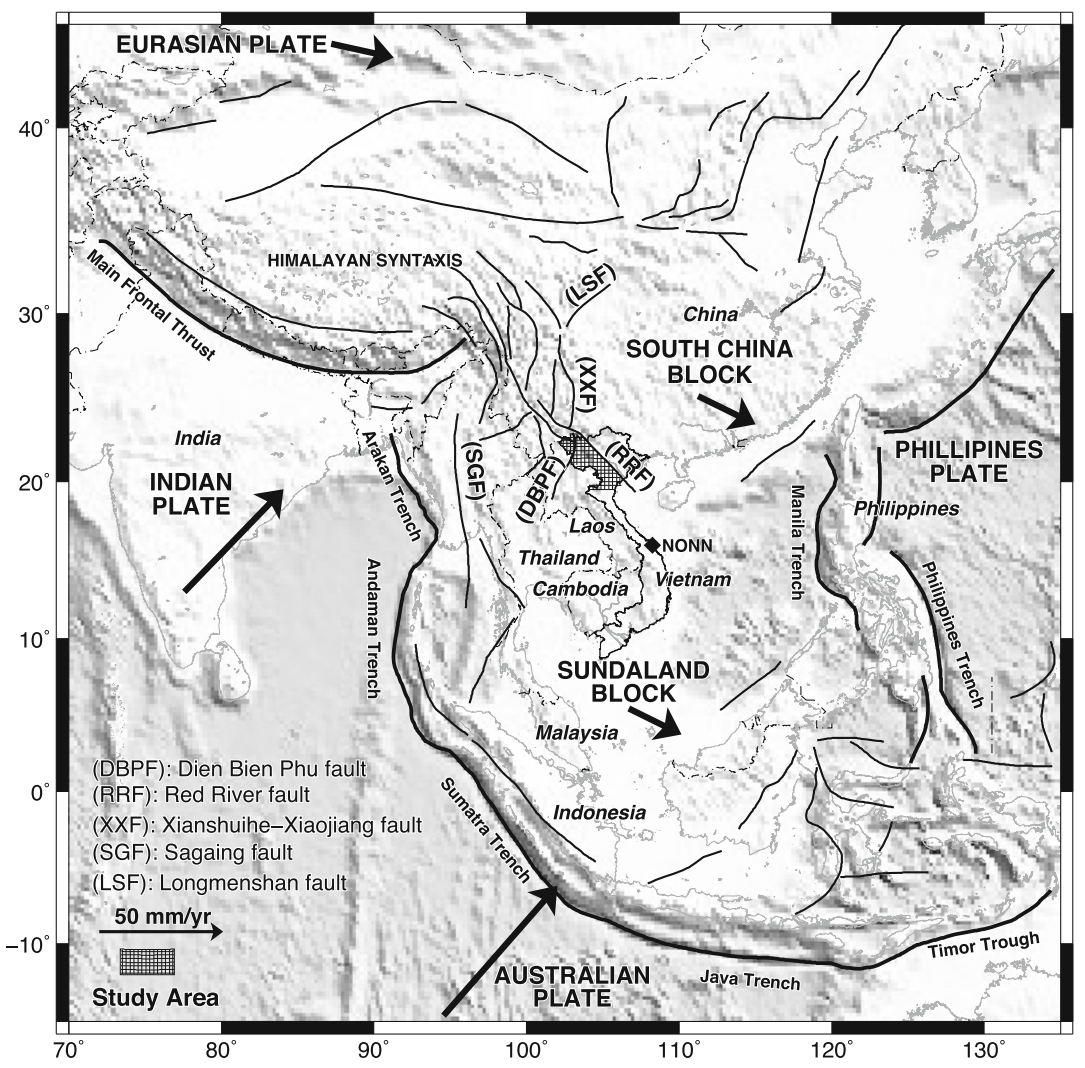

Fig. 1. Topography, main active faults (thick and thin black lines) from Lacassin et al. (1997), Burchfiel (2004), Simons et al. (2007), Yin (2010). Black arrows denote motions of the Eurasian, Australian, Indian plates and the South China and Sundaland blocks in SE Asia and its vicinity, which are computed using the global plate kinematic model NNR-NUVEL-1A (DeMets et al., 1994). Solid diamond represents NONN site, which is one of GEODYSSEA sites (as described by Simons et al., 2007). The hachure shows the study area shown in Figs. 2, 3 and 5.

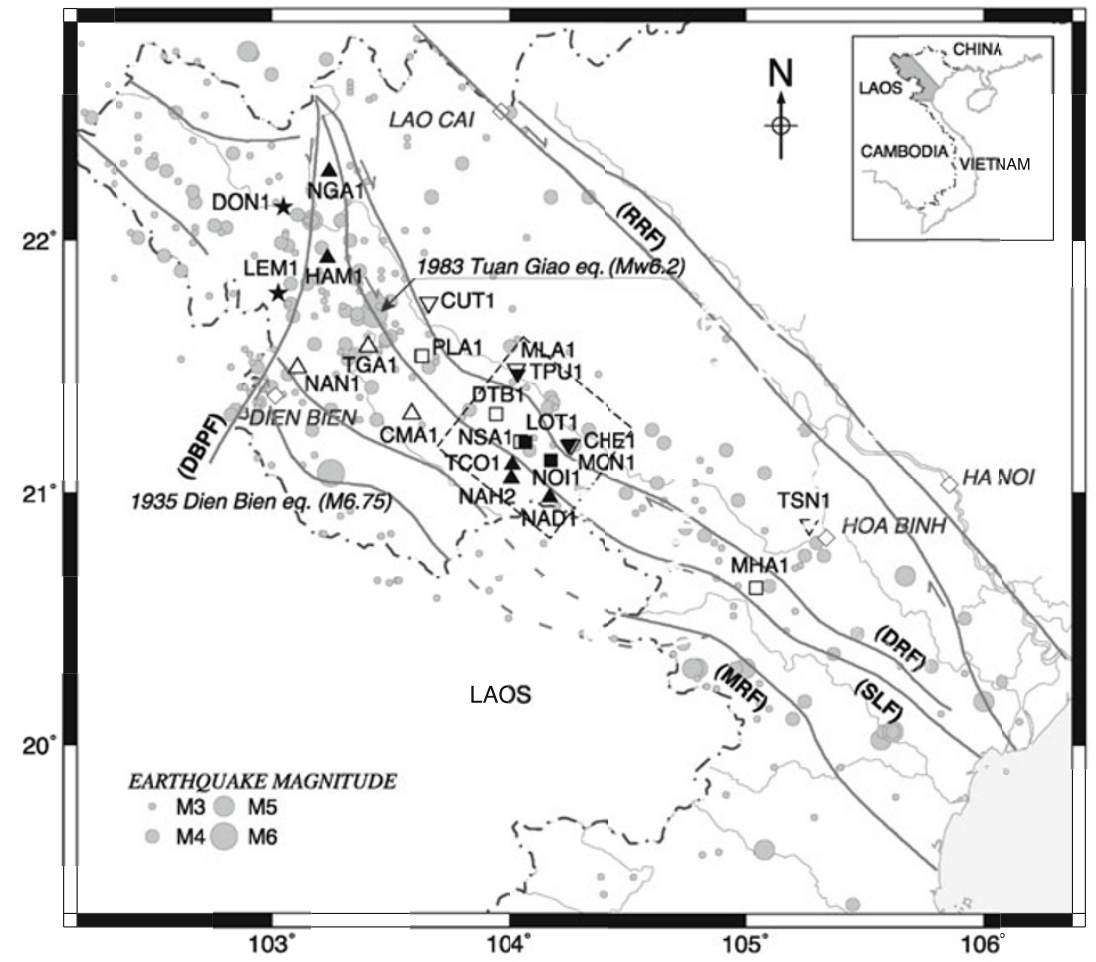

Fig. 2. GPS sites and seismicity map of NWV. Symbols (squares, triangles, inverted triangles and stars) that are classified in Fig. 8 show GPS sites. The black solid symbols denote the sites with long observation, and the white solid symbols are sites with short observation, spans (Table 1). Thick solid and dashed lines depict the main fault systems. Thin lines indicate the permanent rivers and the coast of Vietnam. Small box denotes the location of the study area in Vietnam. Diamond symbols show cities. Rectangle with dashed line shows profiles of the GPS sites in Fig. 7. 
Table 1. GPS data collected at individual sites in NWV.

\begin{tabular}{|c|c|c|c|c|c|c|c|c|c|c|c|}
\hline Site & 2001 & 2002 & 2003 & 2004 & 2005 & 2006 & 2007 & 2009 & 2010 & 2011 & 2012 \\
\hline DON1 & & 9/24/T4 & $4 / 24 / \mathrm{T} 4$ & $4 / 24 / \mathrm{T} 4$ & & & & & $4 / 24 / \mathrm{T} 5$ & $2 / 24 / \mathrm{T} 5$ & $2 / 24 / \mathrm{T} 5$ \\
\hline LEM1 & & 9/24/T4 & $4 / 24 / \mathrm{T} 4$ & $6 / 24 / \mathrm{T} 4$ & & & & $3 / 24 / \mathrm{T} 4$ & $3 / 24 / \mathrm{T} 4$ & $2 / 24 / \mathrm{T} 5$ & \\
\hline NGA1 & & $5 / 24 / \mathrm{T} 4$ & 4/24/T4 & $4 / 24 / \mathrm{T} 4$ & & & & $3 / 24 / \mathrm{T} 5$ & $3 / 24 / \mathrm{T} 5$ & $2 / 24 / \mathrm{T} 5$ & 2/24/T5 \\
\hline HAM1 & & 9/24/T4 & 4/24/T4 & $4 / 24 / \mathrm{T} 4$ & & & & 6/24/T5 & $3 / 24 / \mathrm{T} 5$ & & \\
\hline TPU1 & & & & $3 / 12 / \mathrm{T} 4$ & 4/12/T4 & & & $2 / 24 / \mathrm{T} 5$ & 1/24/T5 & 2/24/T5 & $2 / 24 / \mathrm{T} 5$ \\
\hline LOT1 & 2/12/T4 & $3 / 12 / \mathrm{T} 4$ & & $3 / 12 / \mathrm{T} 4$ & $3 / 12 / \mathrm{T} 4$ & & & $1 / 24 / \mathrm{T} 4$ & 2/24/T5 & 2/24/T5 & 2/24/T5 \\
\hline NAD1 & 1/12/T4 & & & & & & & 2/24/T5 & $3 / 24 / \mathrm{T} 4$ & 2/24/T5 & 2/24/T5 \\
\hline TCO1 & 4/12/T4 & & & & & & & $3 / 24 / \mathrm{T} 5$ & $3 / 24 / \mathrm{T} 5$ & $2 / 24 / \mathrm{T} 5$ & 2/24/T5 \\
\hline NAH2 & & & & & $3 / 12 / \mathrm{T} 4$ & & & 1/24/T5 & & $2 / 24 / \mathrm{T} 5$ & $2 / 24 / \mathrm{T} 5$ \\
\hline MON1 & $3 / 12 / \mathrm{T} 4$ & $3 / 12 / \mathrm{T} 4$ & & $3 / 12 / \mathrm{T} 4$ & $3 / 12 / \mathrm{T} 4$ & & & 1/24/T5 & & 2/24/T5 & $2 / 24 / \mathrm{T} 5$ \\
\hline NOI1 & $3 / 12 / \mathrm{T} 4$ & $3 / 12 / \mathrm{T} 4$ & & $3 / 12 / \mathrm{T} 4$ & $3 / 12 / \mathrm{T} 4$ & & & $1 / 24 / \mathrm{T} 4$ & 2/24/T5 & 2/24/T5 & $2 / 24 / \mathrm{T} 5$ \\
\hline MLA1 & & & & & & & & $2 / 24 / \mathrm{T} 5$ & 2/24/T5 & 2/24/T5 & $2 / 24 / \mathrm{T} 5$ \\
\hline DTB1 & & & & & & & & $2 / 24 / \mathrm{T} 4$ & 2/24/T4 & $3 / 24 / \mathrm{T} 5$ & 2/24/T5 \\
\hline NSA1 & & & & & & & & $3 / 24 / \mathrm{T} 5$ & $1 / 24 / \mathrm{T} 5$ & $2 / 24 / \mathrm{T} 5$ & 2/24/T5 \\
\hline CHE1 & & & & & & & & $3 / 24 / \mathrm{T} 5$ & $2 / 24 / \mathrm{T} 5$ & 1/24/T5 & 2/24/T5 \\
\hline NAN1 & & & & & & & & $2 / 24 / \mathrm{T} 4$ & & $3 / 24 / \mathrm{T} 5$ & 2/24/T5 \\
\hline TGA1 & & & & & & & & & $2 / 24 / \mathrm{T} 5$ & $3 / 24 / \mathrm{T} 5$ & 2/24/T5 \\
\hline CUT1 & & & & & & & & $3 / 24 / \mathrm{T} 5$ & 2/24/T5 & $3 / 24 / \mathrm{T} 5$ & 2/24/T5 \\
\hline CMA1 & & & & & & & & $7 / 24 / \mathrm{T} 5$ & $2 / 24 / \mathrm{T} 5$ & $3 / 24 / \mathrm{T} 5$ & 2/24/T5 \\
\hline PLA1 & & & & & & & & $11 / 24 / \mathrm{T} 5$ & $10 / 24 / \mathrm{T} 5$ & $3 / 24 / \mathrm{T} 5$ & 2/24/T5 \\
\hline MHA1 & & & & & $6 / 24 / \mathrm{T} 4$ & $4 / 24 / \mathrm{T} 4$ & $6 / 24 / \mathrm{T} 4$ & & & & \\
\hline TSN1 & & & & & $4 / 24 / \mathrm{T} 4$ & $4 / 24 / \mathrm{T} 4$ & 4/24/T4 & & & & \\
\hline
\end{tabular}

(number of sessions/session time in hour/receiver type used*)

(*) receiver type used: T4—Trimble 4000 SSE/SSI; T5—Trimble 5700

curred: the 26 December, 2004, M9.1 Sumatra earthquake (e.g., Lay et al., 2005), the 12 May, 2008, M 7.9 Wenchuan earthquake (e.g., Burchfiel et al., 2008), and the 11 March, 2011, M 9.0 Tohoku earthquake (e.g., Simons et al., 2011) at about $2000 \mathrm{~km}, 1000 \mathrm{~km}$, and $4000 \mathrm{~km}$ distance from the study area, respectively. Based on GPS observations as well as a dislocation model for a spherical body, far-field coseismic offsets produced by the 2004 Sumatra and the 2011 Tohoku earthquakes at distances of thousands of kilometers away from the earthquake rupture were shown to be over $1 \mathrm{~mm}$ (e.g., Banerjee et al., 2005; Kreemer et al., 2006; Pollitz et al., 2011). Therefore, the effect of these distant giant earthquakes must be considered to analyze crustal deformation in NWV, where the tectonic deformation rate is not high. This has not been considered in previous studies.

The aim of this study is to clarify the tectonic affiliation of NWV and constrain relative motion across the major fault zones. First, all the GPS phase data in this region are analyzed to get a coordinate time series for each GPS site. Next, the coseismic offsets due to the earthquakes mentioned above are calculated and to offset the time series. Then we calculate the velocity of each GPS site in the ITRF2008 reference frame. Finally, the crustal motion of the area is compared with SC and SU block motions, and the relative motions across the DBPF, SLF, and DRF zones are discussed.

\section{GPS Data Analysis}

We analyze data collected from 2001 to 2012 at 22 campaign GPS sites that were designed to measure displacements along the faults and to study present-day tectonic deformation in NWV (Fig. 2). The spatial distribution of these sites is based on geological considerations and practical accessibility. The sites mainly cover geological structures of the DBPF, SLF, and DRF zones. At these GPS sites, steel benchmarks are installed in bedrock. The Vietnam Institute of Geological Sciences established 11 sites (DON1, LEM1, NGA1, HAM1, TPU1, LOT1, TCO1, NAH2, MON1, NOI1, NAD1) in 2001 (Duong et al., 2006; Tran, 2006; Tran et al., 2012), and two sites (MHA1 and TSN1) near Hoa Binh city in 2005. In addition, the Vietnam Institute of Geophysics established 9 sites (PLA1, CUT1, CMA1, MLA1, DTB1, NSA1, CHE1, NAN1, TGA1) in 2009. These GPS sites have been repeatedly occupied at most once every year. Details of the campaign data used in this study are summarized in Table 1.

We use the BERNESE Version 5.0 software (Dach et al., 2007) for the GPS data to analyze. The 26 IGS sites SELE, BUCU, NICO, POLV, KUNM, WUHN, IRKT, TNML, TRAB, ZECK, DARW, KARR, ALIC, CEDU, TIDB, BAKO, COCO, DAEJ, DGAR, GUAM, IISC, LHAZ, NTUS, PIMO, SHAO, TSKB distributed around the study area are included in our solution as well. Data analysis followed the standard processing strategy (Dach et al., 2011). IGS final orbits, CODE global ionosphere models, IERS Earth Orientation Parameters and ocean tide loading corrections (http://froste.oso.chalmers.se/loading/) are used. The QIF (quasi-ionosphere-free) strategy is chosen to resolve the ambiguities in baseline processing. The program ADDNEQ2 is used to stack normal equation files to produce daily site coordinates. Coordinates of the first 15 IGS sites listed above, which are not affected by large earthquakes, are used to constrain the solution in ITRF2008 (Altamimi et al., 2011). Coordinates of other IGS sites are estimated with the local sites. Each GPS site was occupied for 1 to 11 sessions in each campaign. Thus, we calculate 


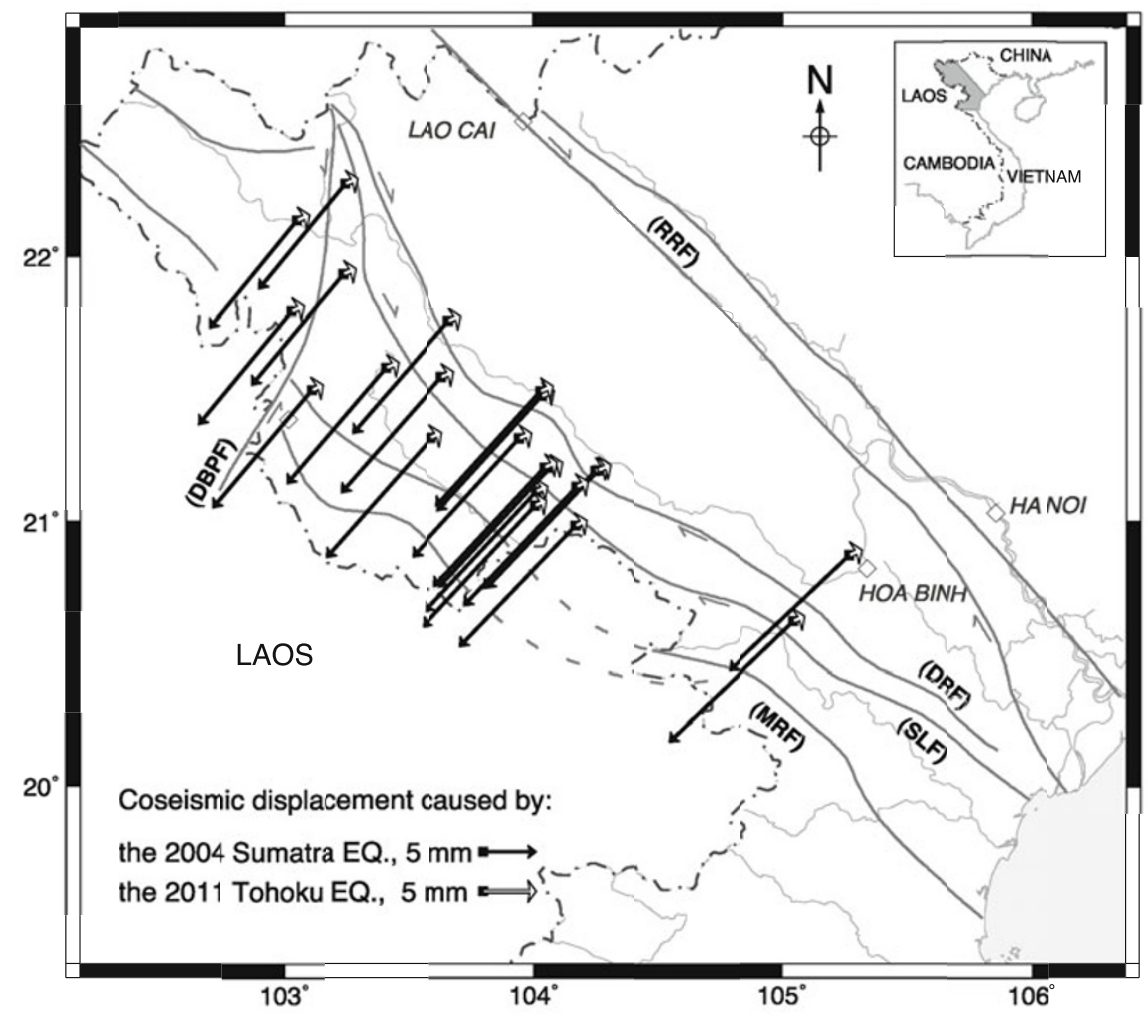

Fig. 3. Calculated horizontal far-field coseismic displacements caused by the 2004 Sumatra and the 2011 Tohoku earthquakes at the GPS sites in NWV. Some descriptions are the same as Fig. 2.

mean campaign coordinates and their standard deviations from daily coordinate solutions for each site. For a campaign with only 1 session, we assume the standard deviation of the campaign coordinate is that of the daily coordinate solution. In our analysis, we assume the eastward and northward components of a site's velocity to be independent. Finally, horizontal velocities and their standard deviations are estimated by the least squares method by assuming white noise model errors (Zhang et al., 1997). There have been many studies demonstrating the importance of colored noise for the estimation of velocity uncertainties. Zhang et al. (1997) pointed out velocity uncertainties with a colored noise model become larger by a factor of 2-6 than those with a white noise model. However, we cannot adequately distinguish a specific noise model for a temporally sparse campaign GPS data set. Thus, the velocity errors in this study may be a little optimistic.

\section{Time-series Correction for Far-field Coseismic Displacements}

Since the GPS sites in NWV have been observed for three or more years, we consider their velocities to be free from the effects of seasonal and long-period noise (Blewitt and Lavallée, 2002). On the other hand, the impact of the farfield coseismic displacements caused by the 2004 Sumatra, the 2008 Wenchuan, and the 2011 Tohoku earthquakes may be significant. So we calculate displacements caused by these earthquakes at the GPS sites using static fault models of these earthquakes. Considering the distance between the source fault and the GPS sites, we apply the elastic dislocation model for a layered spherical earth model developed by Pollitz (1996). We assume physical properties for each layer based on PREM (Dziewonski and Anderson, 1981). As for the source fault model, we use the rupture model D of Kreemer et al. (2006) for the 2004 Sumatra earthquake, the source model for joint geodetic-teleseismic slip of Fielding et al. (2013) for the 2008 Wenchuan earthquake, and the model with additional uplift of Gusman et al. (2012) for the 2011 Tohoku earthquake.

The calculated horizontal displacements show that the 2004 Sumatra earthquake caused southwestward displacements as large as $15 \mathrm{~mm}$ in NWV. Meanwhile, the 2011 Tohoku earthquake produced displacements in the opposite directions, approximately $1.2 \mathrm{~mm}$ to the east and $0.5 \mathrm{~mm}$ to the north, in the same region. The difference in amplitude of the coseismic displacements can be attributed to the distance from each source fault to the study area (Figs. 3 and 4). The horizontal displacements in NWV from the 2008 Wenchuan earthquake are smaller than $1 \mathrm{~mm}$, so they are negligible. Therefore, only the calculated coseismic offsets caused by the 2004 Sumatra and the 2011 Tohoku earthquakes are hereinafter taken into consideration.

We subtract these calculated coseismic offsets from the time series of position, and then estimate an average velocity for each site (Fig. 4). In Table 2, we compare the velocity estimates with and without the coseismic offsets for the two large earthquakes. We refer to these velocities as uncorrected ones, corrected for the 2004 Sumatra earthquake, and corrected for all earthquakes. From these velocities, we calculate the mean velocity corrections and their standard deviations in NWV for each earthquake. The result that offsets of the 2004 Sumatra earthquake affect the ve- 

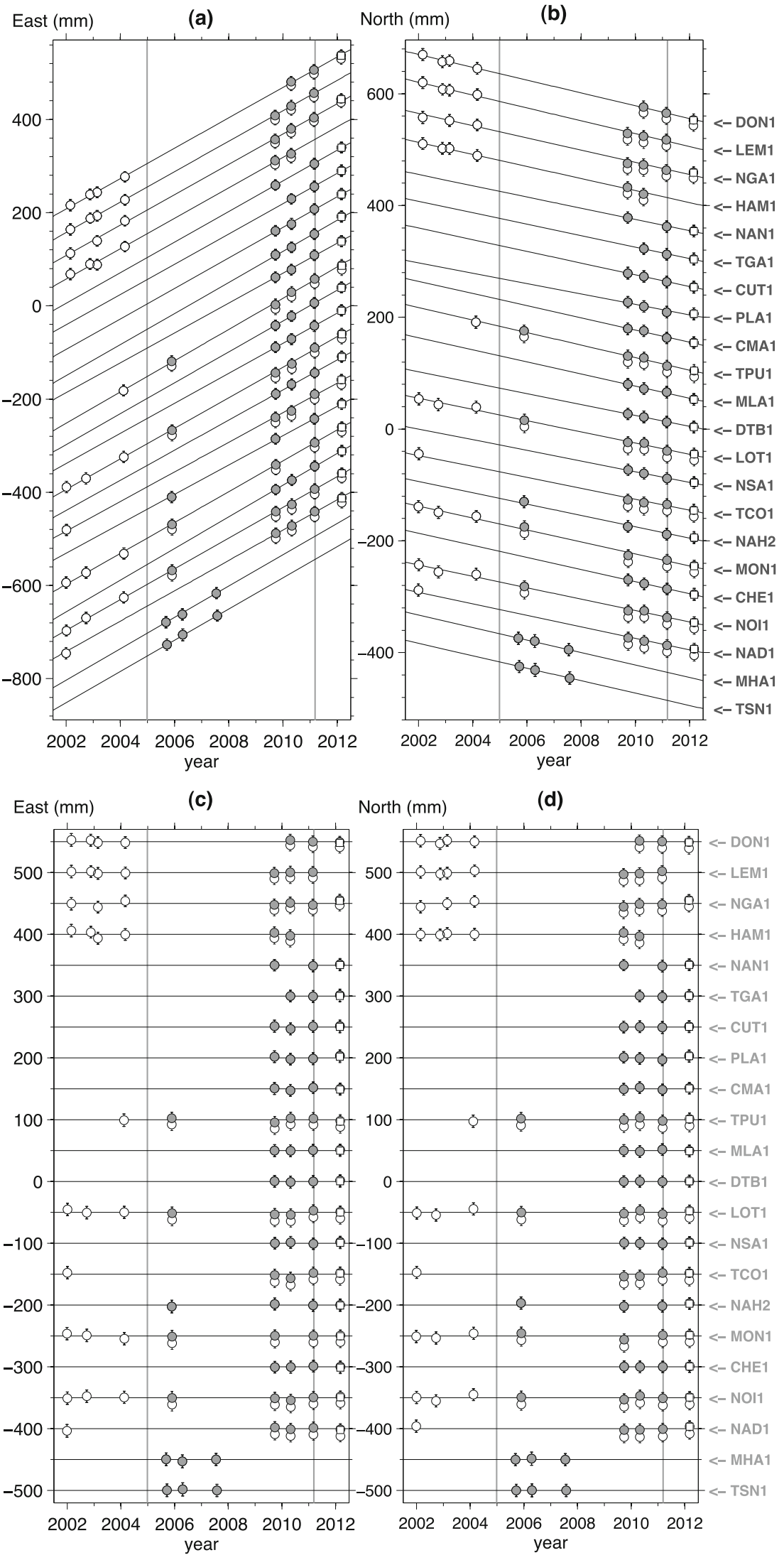

Fig. 4. Horizontal coordinate time series (a, b); time series after removing the linear trend (c, d) of GPS sites (named on the right side of the black solid lines) in NWV in ITRF2008. Vertical solid lines mark the 2004 Sumatra and the 2011 Tohoku earthquakes. Open circles denote the positions of the east and north components before removing the predicted far-field coseismic offsets of these earthquakes. Solid circles show the positions after removing the predicted far-field coseismic offsets caused by the 2004 Sumatra earthquake. Open rectangle shows the positions after removing the predicted far-field coseismic offsets caused by both earthquakes. At the figure scale, Solid circles are covered by open rectangles after 2011. Black solid lines are the best fitting lines for temporal changes of the horizontal coordinates with the correction of the coseismic offsets of the earthquakes. The coordinate uncertainties are shown with a $95 \%$ confidence level. 
Table 2. GPS velocities in the ITRF2008 reference frame and their $1 \sigma$ uncertainties with/without the correction of coseismic offsets for the 2004 Sumatra and the 2011 Tohoku earthquakes at the GPS sites in NWV (mm/yr).

\begin{tabular}{|c|c|c|c|c|c|c|c|c|c|c|c|c|}
\hline \multirow[t]{2}{*}{ Site } & \multicolumn{4}{|c|}{ Uncorrected velocity } & \multicolumn{4}{|c|}{$\begin{array}{l}\text { Velocity corrected for } \\
\text { the } 2004 \text { Sumatra earthquake }\end{array}$} & \multicolumn{4}{|c|}{$\begin{array}{c}\text { Final corrected velocity } \\
\text { (corrected for all earthquakes) }\end{array}$} \\
\hline & $\mathrm{V}_{E}$ & $\mathrm{~V}_{N}$ & $\sigma_{E}$ & $\sigma_{N}$ & $\mathrm{~V}_{E}$ & $\mathrm{~V}_{N}$ & $\sigma_{E}$ & $\sigma_{N}$ & $\mathrm{~V}_{E}$ & $\mathrm{~V}_{N}$ & $\sigma_{E}$ & $\sigma_{N}$ \\
\hline DON1 & 31.6 & -12.6 & 0.2 & 0.1 & 32.7 & -11.3 & 0.2 & 0.1 & 32.6 & -11.4 & 0.2 & 0.1 \\
\hline LEM1 & 31.4 & -13.0 & 0.2 & 0.3 & 32.6 & -11.5 & 0.2 & 0.2 & 32.6 & -11.5 & 0.2 & 0.2 \\
\hline NGA1 & 31.5 & -12.2 & 0.4 & 0.4 & 32.6 & -10.8 & 0.3 & 0.3 & 32.6 & -10.9 & 0.3 & 0.3 \\
\hline HAM1 & 31.5 & -12.1 & 0.5 & 0.2 & 32.8 & -10.6 & 0.5 & 0.2 & 32.8 & -10.6 & 0.5 & 0.2 \\
\hline NAN1 & 32.6 & -10.1 & 1.0 & 0.7 & 32.6 & -10.1 & 1.0 & 0.7 & 32.3 & -10.2 & 1.0 & 0.6 \\
\hline TGA1 & 32.8 & -10.0 & 0.7 & 0.8 & 32.8 & -10.0 & 0.7 & 0.8 & 32.2 & -10.3 & 0.5 & 0.7 \\
\hline CUT1 & 33.1 & -10.0 & 1.0 & 0.5 & 33.1 & -10.0 & 1.0 & 0.5 & 32.8 & -10.1 & 0.9 & 0.5 \\
\hline PLA1 & 32.6 & -10.5 & 0.6 & 0.6 & 32.6 & -10.5 & 0.6 & 0.6 & 32.3 & -10.6 & 0.6 & 0.6 \\
\hline CMA1 & 32.2 & -10.6 & 0.7 & 0.8 & 32.2 & -10.6 & 0.7 & 0.8 & 32.0 & -10.7 & 0.7 & 0.7 \\
\hline TPU1 & 32.7 & -12.1 & 0.3 & 0.3 & 33.5 & -11.2 & 0.3 & 0.3 & 33.4 & -11.3 & 0.3 & 0.3 \\
\hline MLA1 & 33.5 & -10.5 & 0.7 & 0.7 & 33.5 & -10.5 & 0.7 & 0.7 & 33.0 & -10.7 & 0.7 & 0.7 \\
\hline DTB1 & 32.8 & -9.6 & 0.6 & 0.5 & 32.8 & -9.6 & 0.6 & 0.5 & 32.4 & -9.7 & 0.6 & 0.5 \\
\hline LOT1 & 31.7 & -11.2 & 0.4 & 0.4 & 32.8 & -10.0 & 0.2 & 0.3 & 32.7 & -10.0 & 0.2 & 0.3 \\
\hline NSA1 & 32.7 & -9.5 & 0.6 & 0.5 & 32.7 & -9.5 & 0.6 & 0.5 & 32.3 & -9.6 & 0.5 & 0.4 \\
\hline TCO1 & 30.5 & -11.1 & 0.4 & 0.4 & 31.6 & -9.9 & 0.3 & 0.3 & 31.6 & -9.9 & 0.3 & 0.3 \\
\hline NAH2 & 31.7 & -10.3 & 0.4 & 0.5 & 31.7 & -10.3 & 0.4 & 0.5 & 31.6 & -10.3 & 0.4 & 0.4 \\
\hline MON1 & 32.1 & -11.8 & 0.3 & 0.3 & 33.2 & -10.6 & 0.2 & 0.3 & 33.1 & -10.7 & 0.2 & 0.3 \\
\hline CHE1 & 34.1 & -10.5 & 0.8 & 0.5 & 34.1 & -10.5 & 0.8 & 0.5 & 33.7 & -10.7 & 0.8 & 0.5 \\
\hline NOI1 & 31.8 & -11.3 & 0.3 & 0.3 & 32.9 & -10.2 & 0.2 & 0.3 & 32.9 & -10.2 & 0.2 & 0.3 \\
\hline NAD1 & 31.7 & -10.8 & 0.3 & 0.4 & 32.4 & -9.9 & 0.3 & 0.3 & 32.2 & -9.9 & 0.3 & 0.3 \\
\hline MHA1 & 33.7 & -11.2 & 0.8 & 0.7 & 33.7 & -11.2 & 0.8 & 0.7 & 33.7 & -11.2 & 0.8 & 0.7 \\
\hline TSN1 & 33.4 & -11.2 & 0.8 & 0.8 & 33.4 & -11.2 & 0.8 & 0.8 & 33.4 & -11.2 & 0.8 & 0.8 \\
\hline
\end{tabular}

locity estimate by $1.1 \pm 0.2 \mathrm{~mm} / \mathrm{yr}$ for the east component and $1.2 \pm 0.2 \mathrm{~mm} / \mathrm{yr}$ for the north component. On the other hand, the 2011 Tohoku earthquake changes the velocity by only $0.3 \pm 0.2 \mathrm{~mm} / \mathrm{yr}$ and $0.1 \pm 0.1 \mathrm{~mm} / \mathrm{yr}$ for the east and north components, respectively. The final velocity correction and its standard deviation in NWV for the earthquakes are approximately $1.0 \mathrm{~mm} / \mathrm{yr}$ and $0.2 \mathrm{~mm} / \mathrm{yr}$ for the horizontal velocity components, respectively.

In Table 2, velocities over an interval of 2001-2012 and their $1 \sigma$ uncertainties are presented. $1 \sigma$ uncertainties for the velocity components are mostly less than $0.5 \mathrm{~mm} / \mathrm{yr}$ at the GPS sites observed for 4 years or more. Other sites with a shorter observation time, or with low data quality due to measurement problems, have larger uncertainties, but still less than $1.0 \mathrm{~mm} / \mathrm{yr}$, which is precise enough for tectonic interpretation.

\section{Result and Discussion}

\subsection{Crustal movement of NWV and its relation to the blocks}

The final velocity field (Fig. 5(a)) shows that NWV is moving in the east-southeastward direction with an average rate of $34.3 \pm 0.7 \mathrm{~mm} / \mathrm{yr}$ and an azimuth of $\mathrm{N} 108^{\circ} \pm 0.7^{\circ} \mathrm{E}$ in ITRF2008. This area has a significantly different motion from that of the Eurasia plate defined by Calais et al. (2003) $\sim 8 \mathrm{~mm} / \mathrm{yr}$ in the $\mathrm{N} 117^{\circ} \mathrm{E}$ direction. The NWV study area moves independently of the stable Eurasia plate, as do the SC (Wang et al., 2001; Shen et al., 2005) and SU blocks (Michel et al., 2001; Kreemer et al., 2003; Simons et al., 2007).

In order to verify the tectonic affiliation of the study area, we convert the GPS velocities into two different reference frames: the South China frame based on the angular velocity pole reported by Shen et al. (2005), and the Sundaland frame defined by Simons et al. (2007). Shen et al. (2005) and Simons et al. (2007) used velocities in ITRF2000 to define the angular velocities. Plate angular velocity estimates are tied to the frame origin. So we correct for the geocenter difference between ITRF2000 and ITRF2008 using the transformation parameters between ITRF2000 and ITRF2008, produced by the International Terrestrial Reference Frame (http://itrf.ensg.ign.fr/ITRF_solutions/). The result is that the predicted block motions in ITRF2000 at the GPS sites in NWV from the models differ by about 1.7 $\mathrm{mm} / \mathrm{yr}$ in the north component and about $0.1 \mathrm{~mm} / \mathrm{yr}$ in the east component from those in ITRF2008. Then we subtract the predicted block motions in ITRF2008 at the GPS sites. With respect to SC, our GPS sites are moving with a velocity of 1.4 to $2.8 \mathrm{~mm} / \mathrm{yr}$ with an azimuth of $\mathrm{N} 193^{\circ}-$ $261^{\circ} \mathrm{E}$ (Table 3 and Fig. 5(b)). In the SC frame, 12 sites have velocities smaller than $2 \mathrm{~mm} / \mathrm{yr}$. However, the systematic southwestward motion in the northwestern part of the GPS network implies that the GPS network is located in a deformation zone at the periphery of SC.

With respect to SU, our GPS sites coherently show a south-southwestward movement at a rate of 4.4 to 6.3 $\mathrm{mm} / \mathrm{yr}$ to the direction of $\mathrm{N} 191^{\circ}-218^{\circ} \mathrm{E}$ (Table 3 and Fig. 5(c)). The estimated velocities decrease gradually to the east, consistent with the SC-SU rotation pole located to the east of Luzon (Simons et al., 2007). This result is consistent with the left-lateral shear of north-northeast trending faults such as DBPF. 

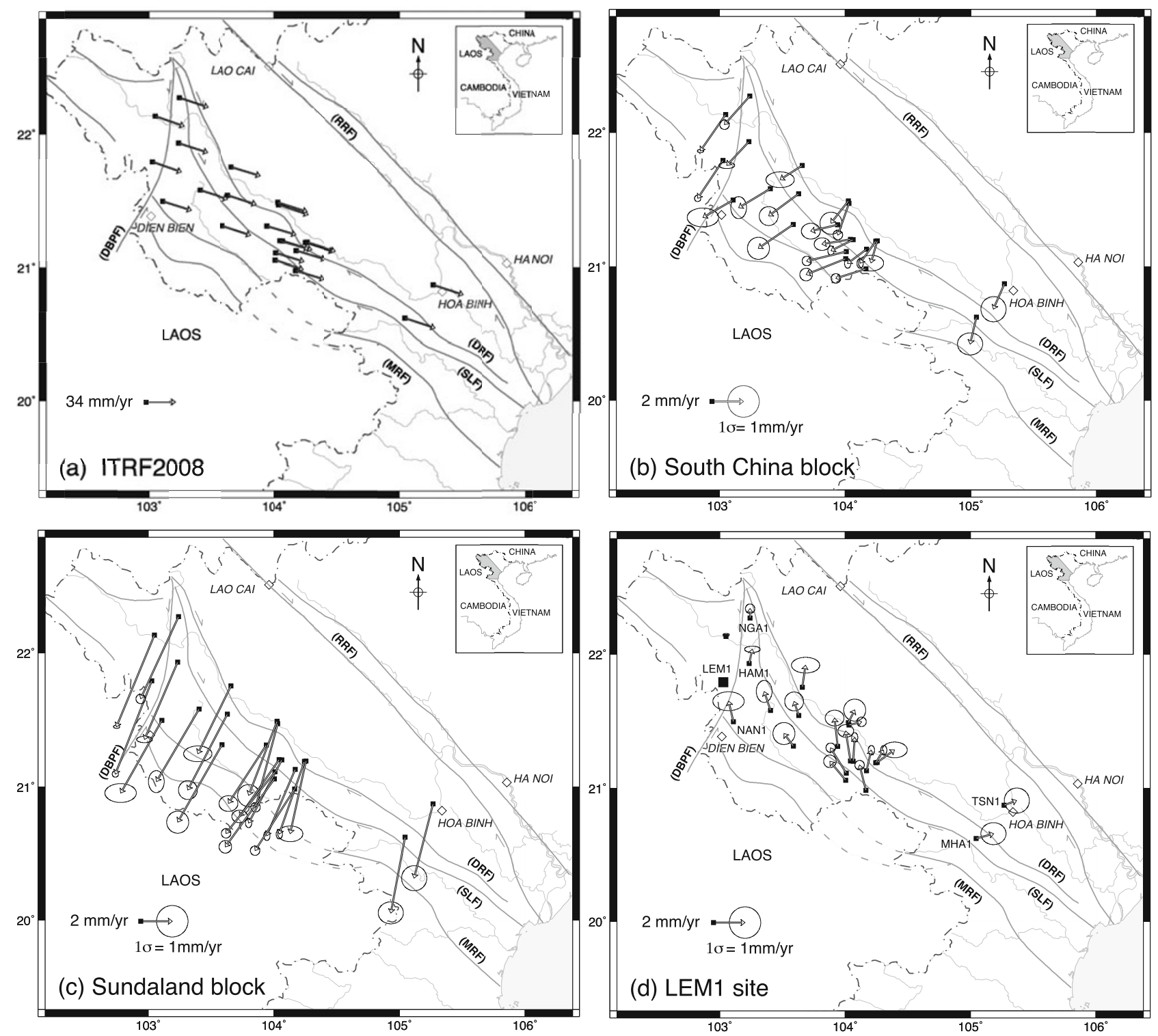

Fig. 5. Velocities in NWV referred to: (a) ITRF2008; (b) the South China block (SC); (c) the Sundaland block (SU); (d) LEM1 site. Some descriptions are the same as Fig. 2.

In the velocity plot referred to site LEM1 (Fig. 5(d)), we clearly see a small but significant differential motion of less than $2 \mathrm{~mm} / \mathrm{yr}$ within the network. The deformation pattern indicates a left-lateral motion across DBPF and a right-lateral motion across DRF and SLF. This deformation field seems to correspond to the seismic activity in this area, as shown in Fig. 2.

\subsection{Slip rate on the faults in NWV}

Next, we evaluate the relative motions across the fault zones around DPBF, DRF, and SLF in NWV. For this purpose, the velocity plot in Fig. 5(d) (LEM1 fixed) is useful since the rigid-block translation common to the whole network has been mostly removed.

Near DBPF, most sites on the east side of DBPF show a significant motion at the $95 \%$ confidence level and their velocity vectors point parallel to the fault, roughly in the northward direction, implying a left-lateral strike-slip across the fault zone. This result is in good agreement with the results of geomorphic and regional structural studies
(Hung and Vinh, 2001; Zuchiewicz et al., 2004; Tung and Thang, 2006, 2008). The left-lateral strike-slip faulting of the DBPF zone can also be clearly seen in the fault-parallel (North) direction profile across the fault (Fig. 6). However, there is no significant displacement in the fault-normal (East) direction. Our GPS relative velocity across DPBF is 0.6-1.9 mm/yr, consistent with the Holocene slip rate of $0.6-2 \mathrm{~mm} / \mathrm{yr}$ (Zuchiewicz et al., 2004), and the Quaternary slip rate of 1.1-3.0 mm/yr (Tung and Thang, 2006, 2008). Lai et al. (2012) pointed out that the present-day kinematics of the DBPF is likely to be the same as in the early Pliocene, and the current study supports their conclusion. In addition, velocities at three sites located along the DBPF (NGA1, HAM1, and NAN1) gradually increase (from 0.6 to $1.3 \mathrm{~mm} / \mathrm{yr}$ ) southward, which agrees with the increasing trend in the Quaternary fault slip rate from the north $(1-1.25$ $\mathrm{mm} / \mathrm{yr}$, Tung and Thang, 2006) to the south $(2.5-3.0 \mathrm{~mm} / \mathrm{yr}$, Tung and Thang, 2008) though there is a systematic difference in the slip rate by a factor of 2 between the geodetic 
Table 3. Velocity difference between the final corrected velocity (corrected for all earthquakes) and two block models (mm/yr).

\begin{tabular}{lcccccc}
\hline \multirow{2}{*}{ Site } & \multirow{2}{*}{ Lon. $\left({ }^{\circ} \mathrm{E}\right)$} & \multirow{2}{*}{ Lat. $\left({ }^{\circ} \mathrm{N}\right)$} & \multicolumn{2}{c}{ South China block } & \multicolumn{2}{c}{ Sundaland block } \\
\cline { 4 - 7 } & & & $\mathrm{V}_{E}$ & $\mathrm{~V}_{N}$ & $\mathrm{~V}_{E}$ & $\mathrm{~V}_{N}$ \\
\hline DON1 & 103.051 & 22.131 & -1.60 & -2.30 & -2.4 & -5.8 \\
LEM1 & 103.029 & 21.792 & -1.60 & -2.40 & -2.3 & -5.9 \\
NGA1 & 103.242 & 22.268 & -1.60 & -1.80 & -2.4 & -5.2 \\
HAM1 & 103.236 & 21.931 & -1.40 & -1.50 & -2.1 & -4.9 \\
NAN1 & 103.108 & 21.497 & -1.90 & -1.10 & -2.6 & -4.6 \\
TGA1 & 103.405 & 21.582 & -2.00 & -1.20 & -2.7 & -4.6 \\
CUT1 & 103.660 & 21.754 & -1.40 & -0.90 & -2.1 & -4.3 \\
PLA1 & 103.631 & 21.542 & -1.90 & -1.40 & -2.5 & -4.8 \\
CMA1 & 103.588 & 21.314 & -2.20 & -1.50 & -2.8 & -4.9 \\
TPU1 & 104.031 & 21.473 & -0.70 & -2.00 & -1.4 & -5.3 \\
MLA1 & 104.026 & 21.489 & -1.10 & -1.40 & -1.8 & -4.7 \\
DTB1 & 103.942 & 21.312 & -1.70 & -0.40 & -2.4 & -3.7 \\
LOT1 & 104.064 & 21.203 & -1.40 & -0.70 & -2.1 & -4.0 \\
NSA1 & 104.044 & 21.204 & -1.80 & -0.30 & -2.5 & -3.6 \\
TCO1 & 104.011 & 21.113 & -2.50 & -0.60 & -3.1 & -3.9 \\
NAH2 & 104.005 & 21.059 & -2.50 & -1.00 & -3.1 & -4.3 \\
MON1 & 104.245 & 21.189 & -1.00 & -1.40 & -1.6 & -4.6 \\
CHE1 & 104.257 & 21.192 & -0.40 & -1.40 & -1.0 & -4.6 \\
NOI1 & 104.172 & 21.131 & -1.20 & -0.90 & -1.8 & -4.2 \\
NAD1 & 104.166 & 20.983 & -1.90 & -0.60 & -2.5 & -3.9 \\
MHA1 & 105.045 & 20.624 & -0.40 & -1.70 & -0.9 & -4.8 \\
TSN1 & 105.269 & 20.872 & -0.70 & -1.60 & -1.2 & -4.7 \\
\hline
\end{tabular}

and geologic results. The agreement between the geodetic and geologic results regarding the spatial distribution of the fault slip-rate along DBPF is a new finding.

In the velocity plot in Fig. 5(d), velocities at MHA1 and TSN1 are not significant at the $95 \%$ confidence level. However, these vectors are directed toward the east or northeast, implying an extension along the DRF-SLF to the west of these two sites. More observation and densification of the GPS network are needed to clarify this issue.

Figure 7 shows GPS velocity profiles across the SLF and DRF within the rectangular zone depicted by the dashed rectangle in Fig. 2, referring to TPU1 as a fixed site. This zone is located far enough from the DBPF that the regional deformation pattern associated with the parallel SLF and DRF fault systems should appear along the profiles. There is no significant displacement in the fault-normal $\left(\mathrm{N} 40^{\circ} \mathrm{E}\right)$ direction. On the other hand, the fault-parallel component $\left(\mathrm{N} 50^{\circ} \mathrm{W}\right)$ clearly shows a right-lateral displacement of 1-2 $\mathrm{mm} / \mathrm{yr}$ across the DRF. The relative motion across the SLF does not seem to be significant. This result is also consistent with the long-term slip rates for SLF $(<1.6 \mathrm{~mm} / \mathrm{yr}$ for the Pleistocene) and DRF (1.1-2.5 mm/yr for the Quaternary) estimated by Hung (2002).

Another question about the relative motion across the fault zones is whether those faults are locked or creeping. If a fault is locked, the velocity pattern is continuous across it, but a step-wise discontinuity appears if the fault is creeping (Savage and Burford, 1973). The steep gradient in the velocity field defines a zone of strain concentration and the locking depth of the fault. We investigate a 2-dimensional calculation of surface deformation with an elastic half-space model. We assume the segments of SLF and DRF that delimit the profile zone (Fig. 2) and the DBPF to be vertically dipping, based on structural exploration data (Minh et al., 2009, 2011). By using site velocities, associated uncertainties and distances to the fault, we estimate the relative motion and locking depth of the fault by minimizing the residuals through a weighted leastsquares inversion. The reduced $\chi^{2}$, defined as the sum of the squared, weighted residuals divided by the number of degrees of freedom, is used to evaluate the consistency of the fit. The estimated model parameters are presented in Table 4. In Fig. 7, three curves corresponding to the best estimate of locking depth, a total creeping case (zero locking depth), and a deeper locking case $(+1 \sigma$ deviation) are shown. All these curves match the observations within the uncertainties, suggesting the model is not well constrained. In the profile zone, only small earthquakes have been observed with a maximum magnitude of 4.9 historically. Also, even in the deeper locking case $(+1 \sigma$ deviation), the locking depth is only $7-8 \mathrm{~km}$, which is quite shallow compared to faults worldwide. So the central SLF and DRF could be creeping. On the other hand, the largest 1983 Tuan Giao earthquake $\left(M_{\mathrm{w}} 6.2\right)$ occurred in the northern portion of SLF (Fig. 2). This may imply a spatial variability of locking condition along the fault. Discriminating between the creeping and locking models for SLF and DRF is difficult with the current geodetic network.

For the DBPF, the inversion reveals a locking depth and slip rate of $15.3 \pm 9.8 \mathrm{~km}$ and $1.8 \pm 0.3 \mathrm{~mm} / \mathrm{yr}$, respectively. Three curves corresponding to locking depths of $5.5,15.3,25.1 \mathrm{~km}$ (the best estimate and $\pm 1 \sigma$ deviations) are plotted in Fig. 6. Hypocenters with depths less than $5.5,15.3$ and $25.1 \mathrm{~km}$ depth are $49 \%, 91 \%$ and $98 \%$ of all events with a magnitude greater than 3.0 that occurred along DBPF, respectively. So the geodetically estimated 

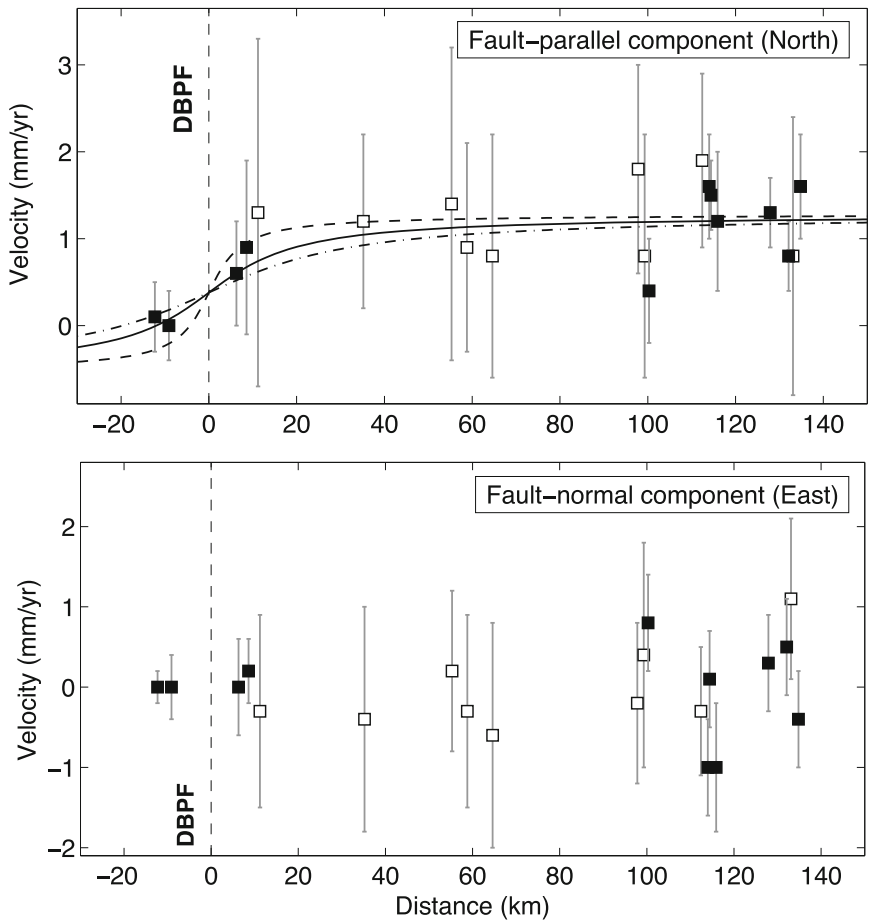

Fig. 6. GPS velocity profiles across the DBPF. (top) Velocity component in the north direction plotted along the same direction, which is considered as the fault-parallel component. The black dashed, solid and dot-dashed lines represent the locking depths of 5.5, 15.3, $25.1 \mathrm{~km}$ (the best estimate and $\pm 1 \sigma$ deviations), respectively. The slip rate of locking models is $1.8 \mathrm{~mm} / \mathrm{yr}$ across DBPF. The estimated model parameters for DBPF are presented in Table 4. (bottom) The velocity component in the east direction. It is the fault-normal component with positive extension. Black and white squares indicate sites with long and short observation intervals, respectively (Table 1). Error bars are for the $95 \%$ confidence level. The vertical dashed lines delineate the location of the DBPF.
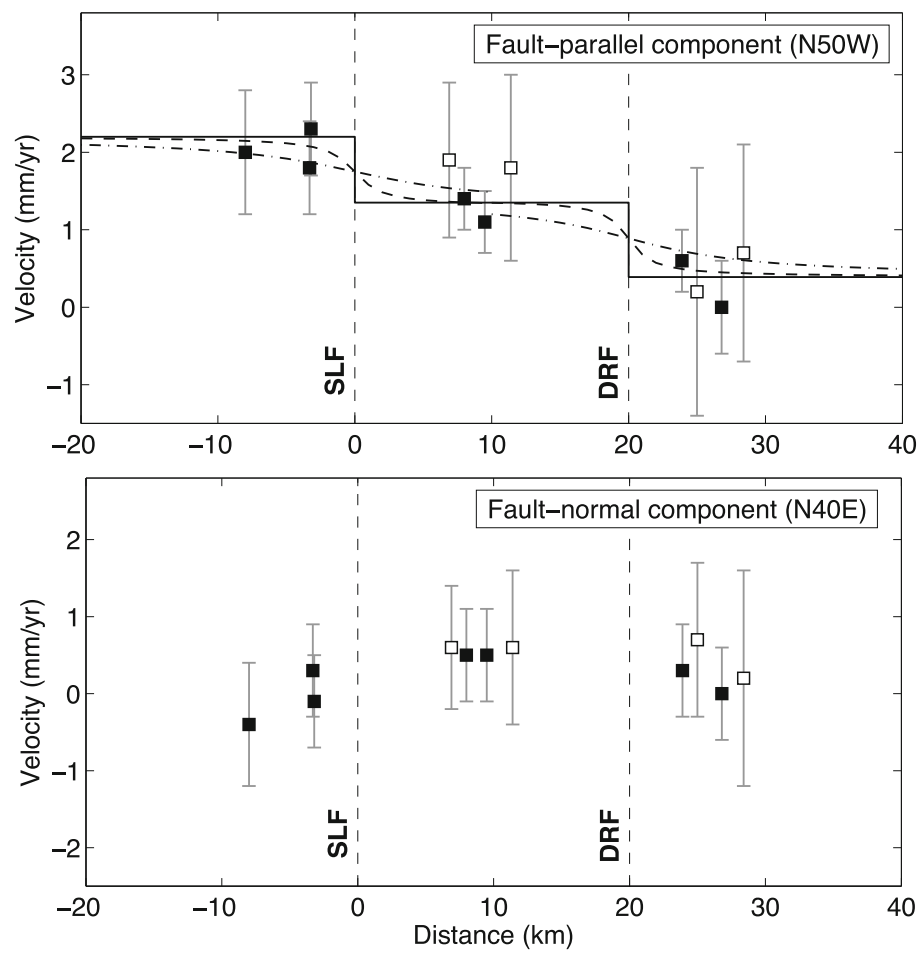

Fig. 7. GPS velocity profiles (of the zone shown in Fig. 2) across the SLF and DRF. (top) Velocity component in N50 W direction plotted along the same direction, which is the fault-parallel component. The black solid line corresponds to the creeping case (zero locking depth) with slip rate of $\sim 1.0 \mathrm{~mm} / \mathrm{yr}$. The dashed lines are the best estimates of locking depths (for SLF $1.5 \mathrm{~km}$ and DRF $1.3 \mathrm{~km}$ ). The dot-dashed lines present the deeper locking cases $(+1 \sigma$ deviation) of SLF and DRF with depths of 7-8 km. The estimated model parameters for the SLF and DRF are presented in Table 4. (bottom) The velocity component in $\mathrm{N}{ }^{\circ} \mathrm{E}$ direction is plotted along the profile. It is the fault-normal component with positive extension. Black and white squares indicate sites with long and short observation intervals, respectively (Table 1). Error bars are for the 95\% confidence level. The vertical dashed lines delineate the location of the SLF and the DRF. 
Table 4. Dislocation models for the SLF, DRF and DBPF based on the GPS data in NWV.

\begin{tabular}{lccc}
\hline Fault & $\begin{array}{c}\text { Slip rate } \\
(\mathrm{mm} / \mathrm{yr})\end{array}$ & $\begin{array}{c}\text { Locking depth } \\
(\mathrm{km})\end{array}$ & $\chi^{2}$ \\
\hline SLF & $0.9 \pm 0.6$ & $1.5 \pm 6.0$ & 0.95 \\
DRF & $1.0 \pm 0.6$ & $1.3 \pm 5.5$ & 1.08 \\
DBPF & $1.8 \pm 0.3$ & $15.3 \pm 9.8$ & 1.23 \\
\hline
\end{tabular}

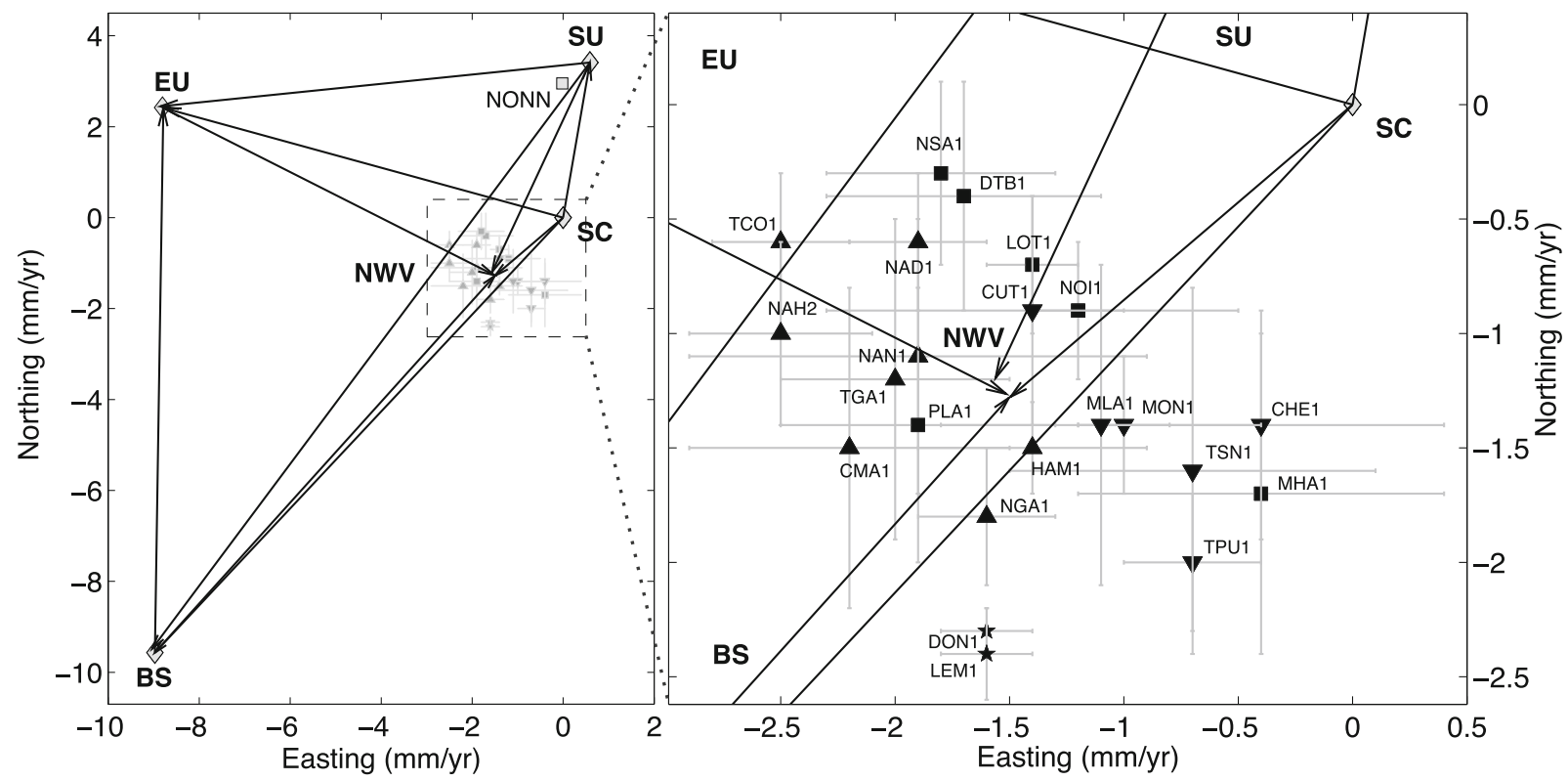

Fig. 8. (left) Relative motion vectors between each pair among NWV, SC, SU, EU and BS. Velocities at the GPS sites in NWV with respect to SC are denoted by the solid circles with $1 \sigma$ error bars. The solid square is the NONN site (Fig. 1). The rectangle shown by the dashed line is shown in detail in the right figure. (right) The GPS sites in NWV are classified into 4 groups geographically, as shown with different symbols. The star, inverted triangle, triangle, and square symbols correspond to the sites of west DBPF, of east DRF, between DBPF, SLF and MRF, and between SLF and DRF, respectively.

locking depth is consistent with the depth distribution of crustal earthquakes. The locking depth of $15.3 \mathrm{~km}$ is also consistent with the magnetotelluric sounding result in the DBPF zone estimated by Minh et al. (2009), in which the ductile regime was estimated at a depth of 20-30 km. From these results, we can infer that the locking depth of 15.3 $\mathrm{km}$ for DBPF is a reliable estimate. In spite of the sparse GPS network, the geodetic measurements in this work are sufficient to determine the current pattern of locking along the strike of DBPF for a comparison with previous studies, such as Duong et al. (2006) and Lai et al. (2012).

\subsection{Classifying the crust movements in NWV accord- ing to geological structure and block motions}

In order to discuss the tectonic affiliation of NWV in a larger framework, we create a vector diagram describing the relative motions between GPS sites in NWV and SC, SU, EU, and the Baoshan sub-block (Shen et al., 2005), as shown in Fig. 8. The result implies that NWV motion is close to that of SC. This study area is in a deformation zone at the periphery of this block. We also consider velocity values with respect to $\mathrm{SC}$ as well as geological structures, such as active fault traces. The GPS sites can be classified into four groups, as shown with different symbols in Fig. 8 (right). We also use the same symbols (squares, triangles, inverted triangles, and stars) to pair with the geographic map in Fig. 2. The inverted triangles (TPU1,
MON1, MLA1, CHE1, CUT1, TSN1) and square groups (NOI1, LOT1, PLA1, NSA1, DTB1, MHA1) representing the sites located east of the DRF and between the SLF and DRF, respectively, do not significantly deviate from SC and can be considered as a part of it. The groups are not clearly separated, probably due to the locked nature of the SLF-DRF fault system. The triangle group (NGA1, HAM1, NAN1, TCO1, NAH2, NAD1, TGA1, CMA1) corresponds to the sites between the DBPF, SLF, and MRF. This group is separated from the former ones. It can be attributed to the distance of each group with respect to the stable SC block. Only PLA1 is an outlier with a large velocity uncertainty. It is probably due to the site located close to the locked zone in the northern portion of SLF where the largest 1983 Tuan Giao earthquake $\left(M_{\mathrm{w}} 6.2\right)$ occurred (Fig. 2). The star group (LEM1, DON1), being west of DBPF, is independent from the other groups, and possibly represents another region, such as southwestern China or Myanmar, that is described as the Baoshan sub-block (BS). It is in agreement with a suggestion of Lai et al. (2012) that DBPF represents the eastern boundary of northern Indochina.

The changing trend of velocity in NWV does not follow the SC-SU combination, implying that this area does not represent the transition between only these two blocks. Rather, it is a transition zone between three blocks, SC, SU, and BS. However, the deformation zone mainly represents 
the SC motion, compared to the other two blocks (Fig. 8 (left)). The transition zone between SC and SU should be spread out toward the south of the study area to reach the site NONN (Figs. 1 and 8) in central Vietnam, which represents SU motion (e.g., Bird, 2003; Simons et al., 2007). The NW-SE trending fault zones DRF and SLF appear to be accommodating part of the relative motion $(<4 \mathrm{~mm} / \mathrm{yr}$ shown in Fig. 8 (left)) between SC and SU. The RRF located further to the northeast, and multiple NW-SE trending faults possibly existing (Cao et al., 2003) to the south of the current study area down to NONN may also be accommodating some of the motion.

\section{Conclusion}

We have analyzed GPS campaign data collected at 22 sites in NWV spanning from 2001 to 2012 in ITRF2008 with a consideration of far-field coseismic displacements caused by the 2004 Sumatra and the 2011 Tohoku earthquakes. We find that the 2004 Sumatra earthquake caused southwestward movement of about $15 \mathrm{~mm}$, while the 2011 Tohoku earthquake moved the area in the opposite direction, by $1.2 \mathrm{~mm}$ to the east and $0.5 \mathrm{~mm}$ to the north. As a result, consideration of the coseismic effects of the two earthquakes reduces the horizontal velocity components by $1.0 \pm 0.2 \mathrm{~mm} / \mathrm{yr}$. It is small but significant for regional deformation between SC and SU whose relative motion is as small as $4 \mathrm{~mm} / \mathrm{yr}$.

From our analysis, we recognize the left-lateral motion of about $2 \mathrm{~mm} / \mathrm{yr}$ across the DBPF, and a right-lateral shear of $1-2 \mathrm{~mm} / \mathrm{yr}$ across SLF and DRF. Our result is consistent with geological studies. In addition, we show, for the first time, a spatial variation of the fault slip-rate along the DBPF. Although the GPS network is still sparse, the displacement patterns across these fault zones fit well with a locking depth of $15.3 \pm 9.8 \mathrm{~km}$ and a slip rate of $1.8 \pm$ $0.3 \mathrm{~mm} / \mathrm{yr}$ for DBPF, and a shallow locking depth (with a large uncertainty) with a right-lateral slip rate of about 1.0 $\pm 0.6 \mathrm{~mm} / \mathrm{yr}$ for SLF and DRF. The hypocenters of $91 \%$ of the earthquakes are at depths less than $15.3 \mathrm{~km}$ along the DBPF. Further densification of the GPS network is necessary to estimate in more detail the fault behavior in NWV.

NWV is moving independently from the stable Eurasia plate with a secular motion of $34.3 \pm 0.7 \mathrm{~mm} / \mathrm{yr}$ to the azimuth of $\mathrm{N} 108^{\circ} \pm 0.7^{\circ} \mathrm{E}$ in ITRF2008. NWV can be considered as a part of the transition boundary zone among three blocks, SC, SU, and BS, although its motion is close to that of SC. The relative motion between SC and SU is partly accommodated by the NW-SE trending fault zones such as SLF, DRF, and RRF, but other faults as far south as the site NONN in central Vietnam could also be responsible. Therefore, in order to clarify the deformation accommodation style between SC and SU, it is necessary to expand the GPS network to the south of the current study area.

Acknowledgments. We appreciate constructive criticism from Kurt Feigl and Jeffery Freymueller. We are grateful to all colleagues of the Institute of Geophysics and Institute of Geological Sciences, Vietnam Academy of Science and Technology who participated in the GPS campaigns to collect data for this work. We thank F. Pollitz for making his spherical coseismic programs available. Most figures in this work were produced using the public-domain GMT software (Wessel and Smith, 1998). This study has been supported by research grants from the National Foundation for Science and Technology Development of Vietnam (ID: 105.09.48.09) and the JSPS RONPAKU (Dissertation PhD) Fellowship from Japan Society for the Promotion of Science (ID: VAST-10931).

\section{References}

Altamimi, Z., X. Collilieux, and L. Métivier, ITRF2008: an improved solution of the International Terrestrial Reference Frame, J. Geod., 85(8), 457-473, doi:10.1007/s00190-011-0444-4, 2011.

Banerjee, P., F. F. Pollitz, and R. Burgmann, The size and duration of the Sumatra-Andaman earthquake from far-field static offsets, Science, 308, 1769-1772, 2005.

Bird, P., An updated digital model of plate boundaries, Geochem. Geophys. Geosyst., 4, 1027, doi:10.1029/2001GC000252, 2003.

Blewitt, G. and D. Lavallée, Effect of annual signals on geodetic velocity, J. Geophys. Res., 107(B7), 2145, doi:10.1029/2001JB000570, 2002.

Burchfiel, B. C., New technology, new geological challenges, Geol. Soc. Am. GSA Today, 14(2), 4-10, 2004.

Burchfiel, B. C., L. H. Royden, R. D. van der Hilst, B. H. Hager, Z. Chen, R. W. King, C. Li, J. Lu, H. Yao, and E. Kirby, A geological and geophysical context for the Wenchuan earthquake of 12 May 2008, Sichuan, People's Republic of China, GSA Today, 18(7), doi:10.1130/GSATG18A.1, 2008.

Calais, E., M. Vergnolle, V. San'kov, A. Lukhnev, A. Miroshnitchenko, S. Amarjargal, and J. Déverchére, GPS measurements of crustal deformation in the Baikal-Mongolia area (1994-2002): Implications for current kinematics of Asia, J. Geophys. Res., 108(B10), 2501, doi:10.1029/2002JB002373, 2003.

Cao, D. T., D. T. Hai, M. X. Bach, and N. G. Thang, Fault system in northern Vietnam, J. Geol., A279(11-12), 8-19, 2003 (in Vietnamese with English Abstract).

Dach, R., U. Hugentobler, P. Fridez, and M. Meindl, Bernese GPS Software Version 5.0, AIUB, University of Bern, 2007.

Dach, R., U. Hugentobler, and P. Walser, Bernese GPS Software Version 5.0, Tutorial, AIUB, University of Bern, 2011.

DeMets, C., R. G. Gordon, D. F. Argus, and S. Stein, Effect of recent revisions to the geomagnetic reversal time scale on estimates of current plate motions, Geophys. Res. Lett., 21(20), 2191-2194. doi:10.1029/94GL02118, 1994.

Duong, C. C., H. S. Yun, and J. M. Cho, GPS measurements of horizontal deformation across the Lai Chau-Dien Bien (Dien Bien Phu) fault, in Northwest of Vietnam, 2002-2004, Earth Planets Space, 58, 523-528, 2006.

Dziewonski, A. M. and D. L. Anderson, Preliminary reference Earth model, Phys. Earth Planet. Inter., 25, 297-356, 1981.

England, P. and P. Molnar, The field of crustal velocity in Asia calculated from Quaternary rates of slip on faults, Geophys. J. Int., 130(3), 551582, doi:10.1111/j.1365-246X.1997.tb01853.x, 1997.

Fielding, E. J., A. Sladen, L. Zhenhong, J. P. Avouac, R. Burgmann, and I. Ryder, Kinematic fault slip evolution source models of the 2008 M7.9 Wenchuan earthquake in China from SAR interferometry, GPS and teleseismic analysis and implications for Longmen Shan tectonics, Geophys. J. Int., 194, 1138-1166, doi:10.1093/gji/ggt155, 2013.

Gusman, A. R., Y. Tanioka, S. Sakai, and H. Tsushima, Source model of the great 2011 Tohoku earthquake estimated from tsunami waveforms and crustal deformation data, Earth Planet. Sci. Lett., 341, 234-242, 2012.

Hung, N. V., Some basic features of neotectonic faults in northwestern Vietnam, Geological Doctoral Thesis, Institute of geological sciences, Hanoi, Vietnam, 2002 (in Vietnamese).

Hung, N. V. and H. Q. Vinh, Moving characteristics of the Lai Chau-Dien Bien Fault zone during Cenozoic, J. Geol., B17-18, 65-77, 2001.

Kreemer, C., W. E. Holt, and A. J. Haines, An integrated global model of present-day plate motions and plate boundary deformation, Geophys. J. Int., 154(1), 8-34, doi:10.1046/j.1365-246X.2003.01917.x, 2003.

Kreemer, C., G. Blewitt, W. C. Hammond, and H. P. Plag, Global deformation from the great 2004 Sumatra-Andaman Earthquake observed by GPS: Implications for rupture process and global reference frame, Earth Planet Space, 58, 141-148, 2006.

Lacassin, R., H. Maluski, P. H. Leloup, P. Tapponnier, C. Hinthong, K. Siribhakdi, S. Chuaviroj, and A. Charoenravat, Tertiary diachronic extrusion and deformation of western Indochina: Structural and 40Ar/39Ar evidence from NW Thailand, J. Geophys. Res., 102(B5), 
10,013-10,037, doi:10.1029/96JB03831, 1997.

Lai, K. Y., Y. G. Chena, and D. D. Lam, Pliocene-to-present morphotectonics of the Dien Bien Phu fault in northwest Vietnam, Geomorphology, 173-174, 52-68, 2012.

Lay, T., H. Kanamori, C. J. Ammon, M. Nettles, S. N. Ward, R. C. Aster, S. L. Beck, S. L. Bilek, M. R. Brudzinski, R. Butler, H. R. DeShon, G. Ekström, K. Satake, and S. Sipkin, The Great Sumatra-Andaman Earthquake of 26 December 2004, Science, 308(5725), 1127-1133, doi:10.1126/science.1112250, 2005.

McCaffrey, R., The tectonic framework of the Sumatran subduction zone, Ann. Rev. Earth Planet. Sci., 37, 345-366, 2009.

Michel, G. W., Yue Qui Yu, Sheng Yuan Zhu, Ch. Reigber, M. Becker, E. Reinhart, W. Simons, B. Ambrosius, Ch. Vigny, N. Chamot-Rooke, X. Le Pichon, P. Morgan, and S. Matheussen, Crustal motion and block behaviour in SE-Asia from GPS measurements, Earth Planet. Sci. Lett., 187, 239-244, 2001.

Minh, L. H., P. V. Ngoc, D. Boyer, N. N. Thuy, L. T. Thanh, N. V. Quan, and G. Marquis, Investigation on the deep geoelectric structure of the Lai Chau-Dien Bien fault zone by magnetotelluric sounding, J. Geol., A311(3-4), 11-21, 2009 (in Vietnamese with English Abstract).

Minh, L. H., D. V. Toan, V. T. Son, N. C. Thang, N. B. Duan, N. H. Thanh, L. T. Thanh, and G. Marquis, Preliminary results of processing the sounding magnetotelluric data of Hoa Binh-Thai Nguyen and Thanh Hoa-Ha Tay profiles, Journal of Earth Science, 33(1), 18-28, 2011 (in Vietnamese with English Abstract).

Molnar, P. and P. Tapponnier, Cenozoic tectonics of Asia: Effects of a continental collision, Science, 189(4201), 419-426, doi:10.1126/science.189.4201.419, 1975.

Pollitz, F., Coseismic deformation from earthquake faulting on a layered spherical Earth, Geophys. J. Int., 125, 1-14, 1996.

Pollitz, F., R. Bürgmann, and P. Banerjee, Geodetic slip model of the 2011 M9.0 Tohoku earthquake, Geophys. Res. Lett., 38, L00G08, doi:10.1029/2011GL048632, 2011.

Savage, J. and R. Burford, Geodetic determination of relative plate motion in central California, J. Geophys. Res., 78, 832-845, 1973.

Shen, Z.-K., J. Lü, M. Wang, and R. Bürgmann, Contemporary crustal deformation around the southeast borderland of the Tibetan Plateau, $J$. Geophys. Res., 110, B11409, doi:10.1029/2004JB003421, 2005.

Simons, M., S. E. Minson, A. Sladen, F. Ortega, J. Jiang, S. E. Owen, L. Meng, J.-P. Ampuero, S. Wei, R. Chu, D. V. Helmberger, H. Kanamori, E. Hetland, A. W. Moore, and F. H. Webb, The 2011 Magnitude 9.0 Tohoku-Oki Earthquake: Mosaicking the Megathrust from Seconds to Centuries, Science, 332(6036), 1421-1425, doi:10.1126/science.1206731, 2011.

Simons, W. J. F., A. Socquet, C. Vigny, B. A. C. Ambrosius, S. Haji Abu, Chawat Promthong, C. Subarya, D. A. Sasito, S. Matheussen, P. Morgan, and W. Spakman, A decade of GPS in Southeast Asia: Resolving Sundaland motion and boundaries, J. Geophys. Res., 112,
B06420, doi:10.1029/2005JB003868, 2007.

Son, L. T., Study on the predicted induced-earthquake in vicinity of Lake Son La. National Project on science and technology, DTDL.2009T/09, Period 2009-2011, Institute of Geophysics, Hanoi, Vietnam, 2012 (in Vietnamese)

Thuy, N. N., Detailed earthquake zoning for northwestern Vietnam, $\mathrm{Na}$ tional Project on science and technology, KC08-10, Period 2001-2005, Institute of Geophysics, Hanoi, Vietnam, 2005 (in Vietnamese).

Tran, D. T., Processing results of GPS measurement data from the Son La and Song Da fault zones, J. Geol., B27, 115-122, Hanoi, 2006.

Tran, D. T., T. Y. Nguyen, C. C. Duong, Q. H. Vy, W. Zuchiewicz, N. Q. Cuong, and N. V. Nghia, Recent crustal movements of northern Vietnam from GPS data, J. Geodyn., doi:10.1016/j.jog.2012.02.009, 2012 (in press)

Tung, V. D. and T. V. Thang, Neotectonic and geodynamic characteristics of Lai Chau town and its adjacency, Journal of Earth Science, 28(2), 121-130, 2006 (in Vietnamese with English Abstract).

Tung, V. D. and T. V. Thang, Characteristics of active fault and neotectonic in Na Pheo-Nam Ty area, J. Earth Sci., 30(1), 73-83, 2008 (in Vietnamese with English Abstract).

Wang, Q., P. Z. Zhang, J. T. Freymueller, R. Bilham, K. M. Larson, X. Lai, X. You, Z. Niu, J. Wu, Y. Li, J. Liu, Z. Yang, and Q. Chen, Present-day crustal deformation in China constrained by Global Positioning System measurements, Science, 294(5542), 574577, doi:10.1126/science.1063647, 2001.

Wessel, P. and W. H. F. Smith, New, improved version of generic mapping tools released, Eos Trans. AGU, 79(47), 579, 1998.

Wilson, P., J. Rais, Ch. Reigber, E. Reinhart, B. A. C. Ambrosius, X. Le Pichon, M. Kasser, P. Suharto, Dato'Abdul Majid, Dato'Paduka Awang Haji Othman Bin Haji Yaakub, R. Almeda, and C. Boonphakdee, Study provides data on active plate tectonics in southeast Asia region, Eos Trans. AGU, 79(45), 545-548, doi:10.1029/98EO00398, 1998.

Yin, A., Cenozoic tectonic evolution of Asia: A preliminary synthesis, Tectonophysics, 488(1-4), 293-325, 2010.

Zhang, J., Y. Bock, H. Johnson, P. Fang, S. Williams, J. Genrich, S. Wdowinski, and J. Behr, Southern California permanent GPS geodetic array: Error analysis of daily position estimates and site velocities, J. Geophys. Res., 102(B8), 18,035-18,055, doi:10.1029/97JB01380, 1997.

Zuchiewicz, W., N. Q. Cuong, B. Andrzej, and M. Marek, Quaternary sediments in the Dien Bien Phu fault zone, NW Vietnam: a record of young tectonic processes in the light of OSL-SAR dating results, Geomorphology, 60(2004) 269-302, 2004.

N. A. Duong (e-mail: duongna@igp-vast.vn), T. Sagiya, F. Kimata, T D. To, V. Q. Hai, D. C. Cong, N. X. Binh, and N. D. Xuyen 